\title{
KOMPARASI CAPITAL ASSET PRICING MODEL DAN FAMA-FRENCH THREE FACTOR MODEL DALAM MEMPREDIKSI RETURN SAHAM
}

\author{
Ni Putu Desy Ratna Dewi ${ }^{1}$ \\ I Wayan Suartana ${ }^{2}$
}

${ }^{1}$ Fakultas Ekonomi dan Bisnis Universitas Udayana (Unud), Bali, Indonesia
$e$-mail: niputudesy47@ gmail.com

\begin{abstract}
ABSTRAK
Tujuan dari penelitian ini adalah untuk membandingkan kemampuan CAPM dan FF3FM dalam memprediksi return saham di Bursa Efek Indonesia. Populasi dalam penelitian ini adalah perusahaan-perusahaan terdaftar di Bursa Efek Indonesia yang termasuk dalam kelompok saham Indeks Kompas 100 pada periode 2012-2016. Hasil penelitian menunjukkan bahwa variabel market risk premium berpengaruh positif terhadap return pada enam portofolio yang dibentuk dalam CAPM dan FF3FM. Variabel size premium berpengaruh positif pada return portofolio $\mathrm{S} / \mathrm{H}, \mathrm{S} / \mathrm{M}$, dan $\mathrm{S} / \mathrm{L}$ dan berpengaruh negatif pada return portofolio $\mathrm{B} / \mathrm{H}, \mathrm{B} / \mathrm{M}$, dan $\mathrm{B} / \mathrm{L}$. Variabel book to market premium berpengaruh positif pada return portofolio $\mathrm{B} / \mathrm{H}, \mathrm{S} / \mathrm{H}$, dan $\mathrm{S} / \mathrm{M}$ dan berpengaruh negatif pada return portofolio $\mathrm{B} / \mathrm{L}$ dan $\mathrm{S} / \mathrm{L}$. Sedangkan variabel book to market premium tidak berpengaruh pada return portofolio B/M. Nilai adjusted $R$ square CAPM dan FF3FM menunjukkan bahwa kemampuan FF3FM lebih baik dalam menjelaskan return dibandingkan CAPM.
\end{abstract}

Kata kunci: Capital Asset Pricing Model, Fama-French Three Factor Model, Indeks Kompas 100, Bursa Efek Indonesia

\begin{abstract}
This study aims to compare the ability of CAPM and FF3FM in predicting stock return in Indonesia Stock Exchange. Population of this study is companies listed on the Indonesia Stock Exchange which are included in the Kompas 100 Index in the period of 2012 - 2016. The results show that market risk premium variable has a positive effect to return on six portfolios formed in CAPM and FF3FM. The variable size premium has a positive effect on $S / H, S / M$, and $S / L$ portfolio return and has negative effect on portfolio return of $B / H, B / M$ and $B / L$. The book to market premium variables have a positive effect on $B / H, S / H$ and $S / M$ portfolio returns and have a negative effect on $B / L$ and $S / L$ portfolio returns. While book to market premium has no effect on B/M portfolio return. The value of adjusted $R$ square $C A P M$ and FF3FM indicates that FF3FM ability in explaining return is better than CAPM.
\end{abstract}

Keywords: Capital Asset Pricing Model, Fama-French Three Factor Model, Indeks Kompas 100, Bursa Efek Indonesia 
Ni Putu Desy Ratna Dewi dan I Wayan Suartana. Komparasi Kinerja...

\section{PENDAHULUAN}

Pasar modal memiliki peran yang penting bagi perekonomian suatu negara. Pasar modal merupakan lembaga yang berfungsi sebagai perantara antara pihak emiten dan investor untuk memerjualbelikan sekuritas (Tandelilin, 2010:26). Pihak emiten akan menawarkan surat berharga dengan melakukan listing terlebih dahulu, demikian sebaliknya investor akan melakukan investasi membeli surat berharga dengan mempertimbangkan return dan risiko.

Kemampuan memahami hubungan antara return dan risiko suatu sekuritas merupakan hal yang sangat penting dan diperlukan oleh investor. Investor selalu berupaya untuk memeroleh informasi dan melakukan berbagai analisis untuk mengurangi ketidakpastian dalam investasinya atau untuk mengurangi risiko yang ada. Model keseimbangan dapat membantu investor untuk memahami bagaimana perilaku investor secara keseluruhan, bagaimana menentukan risiko yang relevan terhadap suatu aset serta hubungan antara risiko dan return harapan untuk suatu aset ketika pasar dalam kondisi seimbang.

Capital Asset Pricing Model (CAPM) merupakan salah satu model keseimbangan yang didasari oleh model portofolio yang dikemukakan oleh Markowitz (1952) dan selanjutnya dikembangkan oleh Sharpe (1964); Lintner (1965); dan Mossin (1969). CAPM menggambarkan hubungan risiko dan return menggunakan satu variabel (disebut juga variabel Beta) untuk menggambarkan risiko. CAPM merupakan model yang secara sederhana dapat menggambarkan realitas hubungan return dan risiko di pasar modal yang bersifat kompleks. CAPM dalam aplikasinya menggunakan faktor risiko tunggal yaitu risiko pasar 
(market risk premium) sebagai tolok ukur risiko dalam mengestimasi return (Pitriyanti, et al. 2015).

Penelitian Choudhary dan Choudary (2010), Wakyiku (2010), Simangunsong dan Wirama (2014) memberikan bukti bahwa koefisien Beta tidak bagus dalam menjelaskan hubungan antara return dan risiko namun model CAPM tetap digunakan secara luas karena mudah dimengerti meskipun pada kenyataannya sulit untuk memenuhi semua asumsi yang dibutuhkan dalam membangun model CAPM (Simangunsong dan Wirama, 2014).

Fama dan French mengembangkan CAPM dalam Fama-French Three Factor Model (FF3FM). Keraguan serta pro kontra atas akurasi Beta pasar sebagai variabel penjelas satu-satunya CAPM dalam mengestimasi return ekspektasi membawa Fama-French Three Factor Model (FF3FM) sebagai multifactor model yang sangat berpengaruh. Jika dalam CAPM perilaku return dan risiko hanya ditentukan oleh pasar, Fama dan French (1993) menambahkan faktor fundamental perusahaan yaitu ukuran perusahaan (firm size) dan book to market. Tiga variabel penjelas dalam estimasi return ekspektasi FF3FM meliputi market risk premium, size premium (diproksikan dengan $\mathrm{SMB}$ ), dan book to market premium (diproksikan dengan HML). Model tersebut mendapat banyak perhatian dan dipandang sebagai alternatif bagi CAPM dalam mengestimasi return saham.

Rossi (2012) meneliti FF3FM pada pasar modal Italia, hasilnya menunjukkan bahwa Beta saja tidak dapat menjelaskan hubungan return dan risiko. Hasilnya mirip dengan penelitian Fama dan French (1998), Rahim dan Abu (2006), dan O’ Brien (2007) yang melakukan pengujian kemungkinan perbedaan 
Ni Putu Desy Ratna Dewi dan I Wayan Suartana. Komparasi Kinerja...

validitas empiris CAPM dan FF3FM di Austalia. Hasilnya menunjukkan bahwa FF3FM memiliki kemampuan yang lebih kuat dibandingkan CAPM dalam menjelaskan variasi return saham.

Beberapa peneliti yang melakukan penelitian FF3FM di Indonesia antara lain dilakukan oleh Susanti (2013), Pitriyanti, et al. (2015), Hardianto dan Suherman (2007). Hasil penelitian tersebut menunjukkan bahwa FF3FM valid digunakan di Indonesia. Hasil yang berbeda ditunjukkan oleh penelitian yang dilakukan oleh Sudiyatno dan Irsad (2013), Saputra dan Murtini (2008) yang menunjukkan bahwa FF3FM tidak valid di Indonesia. Secara teori FF3FM seharusnya lebih efektif dibandingkan CAPM karena FF3FM merupakan model pengembangan dari CAPM. Namun, pada prakteknya terdapat beberapa penelitian yang menunjukkan FF3FM tidak lebih baik dari CAPM.

Berdasarkan latar belakang tersebut, adapun tujuan penelitian ini adalah untuk membandingkan kembali keakuratan kinerja CAPM dan FF3FM dalam memprediksi return saham. Tingkat akurasi kedua model diukur dengan adjusted $R$ square. Jika adjusted $R$ square dengan menggunakan FF3FM lebih besar dari CAPM, maka FF3FM lebih mampu menjelaskan estimasi return dibandingkan dengan CAPM.

Penelitian ini dilakukan pada kelompok saham Indeks Kompas 100 di Bursa Efek Indonesia periode 2012 - 2016. Alasan pemilihan objek penelitian tersebut adalah karena penelitian terdahulu belum ada yang meneliti kinerja model CAPM dan FF3FM pada kelompok saham Indeks Kompas 100. Sekarwati dan Margasari (2016) menyatakan bahwa saham-saham yang terdapat di Indeks 
Kompas 100 merupakan saham-saham utama penggerak Indeks Harga Saham Gabungan (IHSG). Nilai kapitalisasi pasar saham-saham Indeks Kompas 100 mewakili sekitar 70\% - 80\% dari total nilai kapitalisasi pasar keseluruhan saham yang terdaftar di Bursa Efek Indonesia (BEI).

Variabel market risk premium yang digunakan dalam CAPM dan FF3FM merupakan selisih antara return pasar dengan return bebas risiko. Market risk premium dengan kata lain merupakan faktor tambahan risiko perusahaan. Saat keadaan ekuilibrium, required rate of return akan dipengaruhi oleh risiko dari saham atau sekuritas. Risiko pasar merupakan risiko yang berkaitan dengan perubahan yang terjadi di pasar secara keseluruhan. Perubahan pasar tersebut akan memengaruhi variabilitas return suatu investasi.

Konsep CAPM yaitu semakin tinggi risiko, semakin tinggi tingkat keuntungan yang diharapkan oleh investor, high risk high return. Hal ini berarti saham-saham yang berisiko tinggi diharapkan akan menghasilkan return yang tinggi pula, karena investor harus menanggung risiko yang lebih besar. Penelitian yang dilakukan Gan, et al. (2013) memberikan hasil bahwa market risk premium berpengaruh positif terhadap return. Yeswanto dan Mardani (2015) melakukan pengujian terhadap model tiga faktor Fama \& French pada perusahaan LQ45. Hasilnya menunjukkan bahwa return pasar berpengaruh positif terhadap return saham.

Berdasarkan teori dan penelitian empiris tersebut maka hipotesis pertama dalam penelitian ini adalah: 
Ni Putu Desy Ratna Dewi dan I Wayan Suartana. Komparasi Kinerja...

$\mathrm{H}_{1}$ : Market risk premium berpengaruh positif terhadap return saham perusahaan pada kelompok saham Indeks Kompas 100 dalam CAPM dan FF3FM.

Size premium merupakan selisih return portofolio saham berkapitalisasi pasar kecil dan saham berkapitalisasi pasar besar, yang disebut sebagai Small Minus Big (SMB). Fama dan French (1992) selaras dengan Banz (1981) menemukan hubungan negatif antara return dengan size, saham berkapitalisasi pasar kecil memiliki return lebih tinggi dibanding saham berkapitalisasi besar. Investor memiliki persepsi bahwa perusahaan dengan kapitalisasi kecil cenderung tidak stabil dan lebih sensitif terhadap berbagai risiko dibanding perusahaan dengan kapitalisasi besar. Ketidakpastian dan risiko yang lebih besar ini mendorong investor untuk mensyaratkan tambahan return yang lebih besar juga dibanding perusahaan dengan kapitalisasi besar yang jauh lebih stabil dan lebih tidak berisiko.

Davis, et al. (2000) melakukan pengujian terhadap market, size dan value premium pada pasar modal di Amerika periode 1925-1996 hasilnya size premium berpengaruh terhadap return. Drew, et al. (2003) melakukan penelitian mengenai pengaruh size premium terhadap return pada Shanghai Stock Exchange hasilnya variabel size premium berpengaruh terhadap return. Harsalim (2013) melakukan penelitian untuk menguji pengaruh market risk, size, book to market ratio, dan earnings price ratio terhadap return pada perusahaan sektor miscellaneous industry di BEI periode 2006-2012 hasilnya variabel size premium berpengaruh terhadap return. Yeswanto dan Mardani (2015) melakukan pengujian terhadap 
model tiga faktor Fama \& French pada perusahaan di LQ45 hasilnya menemukan bahwa ukuran kapitalisasi pasar berpengaruh terhadap return saham.

Berdasarkan teori dan penelitian empiris tersebut maka hipotesis kedua dalam penelitian ini adalah:

$\mathrm{H}_{2}$ : $\quad$ Size premium berpengaruh terhadap return saham perusahaan pada kelompok saham Indeks Kompas 100 dalam FF3FM.

Book to market premium merupakan selisih return portofolio saham dengan book to market tinggi dan portofolio saham dengan book to market rendah yang disebut sebagai High Minus Low (HML). Selaras dengan penelitian Stattman (1980), Fama dan French (1992) memeroleh hubungan positif antara average return dan book to market, artinya bahwa saham dengan rasio book to market tinggi cenderung memiliki rata-rata pengembalian yang lebih tinggi dibanding perusahaan dengan rasio book to market rendah.

Rasio book to market menunjukkan seberapa jauh suatu perusahaan mampu menciptakan nilai perusahaan relatif terhadap jumlah modal yang diinvestasikan. Rasio ini merupakan perbandingan antara nilai buku equity dengan nilai pasar dari equity. Jika nilai pasar lebih tinggi dari nilai buku, maka investor akan optimis terhadap prospek masa depan saham tersebut. Sebaliknya, jika nilai pasar lebih rendah dari nilai buku, maka investor menjadi pesimis terhadap masa depan saham tersebut. Oleh karena itu, saham dengan rasio book to market yang tinggi memiliki risiko yang relatif tinggi daripada saham dengan rasio book to market yang lebih rendah, sehingga investor akan mengharapkan return yang lebih tinggi terhadap saham yang memiliki rasio book to market yang tinggi. 
Ni Putu Desy Ratna Dewi dan I Wayan Suartana. Komparasi Kinerja...

Davis, et al. (2000) melakukan pengujian terhadap market, size dan value premium pada pasar modal di Amerika periode 1925-1996 hasilnya menunjukkan bahwa rasio book to market berpengaruh terhadap return saham. O'Brien (2007) melakukan penelitian dengan menganalisis size dan pengaruh book to market dan kemampuan model tiga faktor Fama \& French (1993) untuk menjelaskan return di pasar modal Australia periode 1981-2005. Hasil penelitian tersebut menunjukkan bahwa rasio book to market berpengaruh terhadap return saham. Penelitian Stattman (1980) dan Fama (1992) juga memperkuat bukti bahwa book to market berkorelasi positif dengan return sekuritas.

Berdasarkan teori dan penelitian empiris tersebut maka hipotesis ketiga dalam penelitian ini adalah:

$\mathrm{H}_{3}$ : $\quad$ Book to market premium berpengaruh terhadap return saham perusahaan pada kelompok saham Indeks Kompas 100 dalam FF3FM

Fama dan French (1992) membuat sebuah penelitian yang sangat berpengaruh hingga sekarang dengan mengkombinasikan variabel size, leverage, E/P, book to market, dan Beta dalam sebuah penelitian single cross sectional. Penelitian tersebut menghasilkan hubungan negatif antara ukuran perusahaan (firm size) dan Beta, sedangkan korelasi Beta dan return justru tidak tampak. Hasil tersebut kontradiktif dengan CAPM.

Mengetahui bahwa Beta bukan satu-satunya variabel yang mampu menjelaskan return rata-rata, maka tujuan penelitian Fama dan French selanjutnya adalah mendapatkan variabel yang lebih baik dari Beta. Fama dan French membandingkan kekuatan dari size, leverage, E/P, book to market equity, dan 
Beta dalam cross-sectional regressions selama periode 1963-1990. Hasil penelitian tersebut adalah bahwa book to market equity dan size memiliki hubungan paling kuat dengan return.

Bhatnagar dan Ramlogan (2012) meneliti tentang perbandingan CAPM dan FF3FM di UK, hasilnya menunjukkan bahwa FF3FM lebih baik dalam menjelaskan variasi return saham dibandingkan dengan CAPM pada perusahaanperusahan di Inggris. Hasil penelitian Priyantini, et al. (2015) menunjukkan bahwa penambahan variabel bebas Fama and French selalu dapat menaikkan nilai determinasi pada setiap portofolio. Sehingga dalam penelitian tersebut diperoleh hasil bahwa FF3FM lebih baik daripada CAPM. Susanti (2013) juga melakukan pengujian FF3FM di Indonesia. Hasil penelitian menunjukkan bahwa secara simultan keseluruhan variabel FF3FM memiliki pengaruh terhadap excess return perusahaan di Indonesia yang sahamnya terdapat di LQ 45 Tahun 2005 - 2009.

Berdasarkan teori dan penelitian empiris tersebut maka hipotesis keempat dalam penelitian ini adalah:

$\mathrm{H}_{4}$ : Kinerja FF3FM lebih baik dibandingkan CAPM dalam memprediksi return saham perusahaan pada kelompok saham Indeks Kompas 100.

\section{METODE PENELITIAN}

Jenis penelitian ini berdasarkan pada pendekatan kuantitatif dengan metode deskriptif komparatif. Tujuan dari penelitian deskriptif adalah untuk membuat deskripsi, gambaran secara sistematis, faktual dan akurat mengenai fakta-fakta, sifat-sifat serta hubungan antar fenomena yang diselidiki. Dalam metode deskriptif, peneliti dapat membandingkan fenomena-fenomena tertentu 
Ni Putu Desy Ratna Dewi dan I Wayan Suartana. Komparasi Kinerja...

sehingga merupakan suatu studi komparatif. Sugiyono (2012: 54) menyatakan bahwa penelitian komparatif adalah penelitian yang membandingkan keberadaan satu variabel atau lebih pada dua atau lebih sampel yang berbeda, atau pada waktu yang berbeda. Definisi di atas sesuai dengan tujuan dari penelitian ini yaitu untuk membandingkan kinerja antara CAPM dan FF3FM dalam memprediksikan return saham.

Variabel yang akan dianalisis dalam penelitian ini dibagi menjadi dua variabel yaitu variabel dependen dan independen. Variabel dependen terdiri dari return portofolio saham kelompok $\mathrm{S} / \mathrm{H}, \mathrm{S} / \mathrm{M}, \mathrm{S} / \mathrm{L}, \mathrm{B} / \mathrm{H}, \mathrm{B} / \mathrm{M}$, dan B/L. Sedangkan variabel independennya adalah market risk premium, size premium dan book to market premium. Variabel tersebut akan diamati selama periode 2012-2016 dengan menggunakan harga saham penutupan yang disesuaikan bulanan.

Penelitian ini membagi sampel ke dalam enam kelompok portofolio berdasarkan ukuran dan book to market menjadi portofolio $\mathrm{S} / \mathrm{H}, \mathrm{S} / \mathrm{M}, \mathrm{S} / \mathrm{L}, \mathrm{B} / \mathrm{H}$, B/M, dan B/L. Pembentukan portofolio merujuk pada penelitian Fama dan French (1993) dengan tujuan untuk menentukan apakah pengaruh variabel size dan book to market ratio dapat ditangkap oleh return portofolio yang dibentuk dengan meniru portofolio SMB dan HML. Fama dan French (1993) memutuskan untuk membagi perusahaan ke dalam tiga kelompok berdasarkan book to market dan dua kelompok berdasarkan size.

Pembentukan portofolio ini mengacu pada hasil penelitian Fama dan French (1992) yang menyatakan bahwa book to market mempunyai peran yang lebih kuat dibandingkan size dalam menjelaskan rata-rata return. Pembagian book 
to market menjadi tiga dilakukan untuk menguji apakah pilihan ini sensitif terhadap hasil penelitian dan hasilnya variasi return dapat dijelaskan dengan baik oleh variasi book to market yang dibagi tiga. Membagi tiga book to market dapat menyebabkan data yang diperlukan untuk melakukan perhitungan hanya $60 \%$ dibandingkan jika dibagi dua. Penggunaan data yang lebih sedikit akan lebih memudahkan untuk melakukan perhitungan book to market premium.

Portofolio S/L terdiri dari kelompok saham dengan kapitalisasi pasar kecil dan memiliki BE/ME rendah. Portofolio S/M terdiri dari kelompok saham dengan kapitalisasi pasar kecil dan memiliki BE/ME medium. Portofolio S/H terdiri dari kelompok saham dengan kapitalisasi pasar kecil dan memiliki BE/ME tinggi. Portofolio B/L terdiri dari kelompok saham dengan kapitalisasi pasar besar dan memiliki BE/ME rendah. Portofolio B/M terdiri atas kelompok saham dengan kapitalisasi pasar besar dan memiliki BE/ME medium. Portofolio terakhir yaitu B/H merupakan kelompok saham dengan kapitalisasi pasar besar dan memiliki $\mathrm{BE} / \mathrm{ME}$ tinggi.

Data yang digunakan dalam penelitian ini merupakan data sekunder. Sumber data yang dipergunakan dalam penelitian ini meliputi Website Bursa Efek Indoneisa (data daftar perusahaan yang termasuk dalam kelompok saham Indeks Kompas 100, listed share, market capitalization dan book value), website yahoo finance (data harga penutupan bulanan disesuaikan dan IHSG bulanan), dan website Bank Indonesia (data tingkat suku bunga bulanan Sertifikat Bank Indonesia). 
Ni Putu Desy Ratna Dewi dan I Wayan Suartana. Komparasi Kinerja...

Populasi penelitian ini adalah perusahaan-perusahaan terdaftar di Bursa Efek Indonesia yang termasuk dalam kelompok saham Indeks Kompas 100 pada periode 2012-2016. Jumlah populasi penelitian sebanyak 100 perusahaan dan yang memenuhi kriteria purposive sampling untuk menjadi sampel sebanyak 59 perusahaan seperti yang ditampilkan pada Tabel 1.

Tabel 1.

Jumlah Perusahaan Sampel

\begin{tabular}{clc}
\hline No. & \multicolumn{1}{c}{ Keterangan } & Jumlah \\
\hline 1. & Jumlah perusahaan yang termasuk dalam kelompok saham Indeks & 100 \\
& Kompas 100 & \\
2. & $\begin{array}{l}\text { Tidak terdaftar konsisten dalam kelompok saham Indeks Kompas } 100 \text { di } \\
\text { Bursa Efek Indonesia selama periode 2012 - 2016 }\end{array}$ \\
3. & Terlambat menerbitkan laporan keuangan periode 2016 \\
4. & Memiliki rasio book to market equity negatif selama periode penelitian & $(1)$ \\
\hline & Jumlah sampel & $\mathbf{5 9}$ \\
\hline
\end{tabular}

Sumber: data yang diolah

Instrumen pengumpulan data yang dilakukan dengan menggunakan metode observasi non partisipan. Metode ini dilakukan dengan cara mencatat dan mempelajari uraian-uraian dari buku-buku, jurnal, tesis, mengakses PT. Bursa Efek Indonesia (BEI) melalui www.idx.co.id, mengakses website Yahoo Finance melalui http://finance.yahoo.com dan website Bank Indonesia melalui http://www.bi.go.id/.

Metode analisis pada penelitian ini adalah deskriptif komparatif dengan pendekatan kuantitatif. Alat analisis kuantitatif yang digunakan adalah statistik deskriptif, uji asumsi klasik, dan analisis regresi. 


\section{HASIL DAN PEMBAHASAN}

Hasil analisis deskriptif dapat dilihat pada Tabel 2.

\section{Tabel 2.}

\section{Statistik Deskriptif Variabel Penelitian}

\begin{tabular}{ccc}
\hline Variabel & Rata-rata Return & Standar Deviasi \\
\hline B/H & $-0,76 \%$ & $5,90 \%$ \\
B/M & $0,44 \%$ & $5,98 \%$ \\
B/L & $0,70 \%$ & $4,53 \%$ \\
S/H & $-0,57 \%$ & $8,38 \%$ \\
S/M & $0,66 \%$ & $7,91 \%$ \\
S/L & $1,62 \%$ & $4,78 \%$ \\
Rm - Rf & $0,11 \%$ & $3,71 \%$ \\
SMB & $1,34 \%$ & $12,74 \%$ \\
HML & $-3,64 \%$ & $9,71 \%$ \\
\hline
\end{tabular}

Sumber: data yang diolah, 2017

Tabel 2 menunjukkan bahwa selama periode pengamatan 60 bulan, ratarata nilai $\mathrm{Rm}-\mathrm{Rf}$ (rata-rata premi per unit beta pasar) adalah $0,11 \%$ dengan nilai standar deviasi $3,71 \%$. SMB memiliki rata-rata premium positif $1,34 \%$ dengan standar deviasi $12,74 \%$. Hasil perhitungan SMB yang positif menunjukkan bahwa saham berkapitalisasi kecil lebih baik daripada saham berkapitalisasi besar. Portofolio HML memiliki rata-rata return negatif yaitu $-3,64 \%$ dengan standar deviasi 9,71\%. Hasil perhitungan HML yang negatif menunjukkan bahwa saham dengan book to market tinggi (High) menghasilkan return lebih rendah daripada saham dengan book to market rendah (Low).

Gambar 1 menyajikan perbandingan rata-rata return saham yang termasuk dalam portofolio Small dan rata-rata return saham yang termasuk dalam portofolio Big. 
Ni Putu Desy Ratna Dewi dan I Wayan Suartana. Komparasi Kinerja...

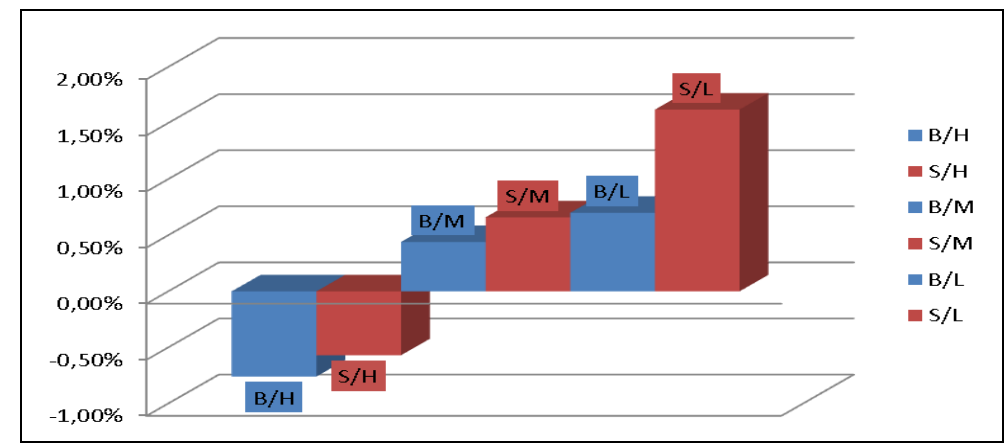

Gambar 1. Portofolio Small vs Porfolio Big

Sumber: data yang diolah, 2017

Pada Gambar 1 terlihat jelas bahwa berdasarkan rata-rata return yang diperoleh, perusahaan yang termasuk dalam small firm size secara umum lebih bagus dibandingkan big firm size. Hasil penelitian ini konsisten dengan penelitian Fama dan French $(1993,1996)$ tentang small firm effect di pasar modal Amerika yaitu perusahaan dengan kapitalisasi pasar kecil mengungguli perusahaan dengan kapitalisasi pasar besar.

Gambar 2 menyajikan perbandingan rata-rata return saham yang termasuk dalam portofolio High dan rata-rata return saham yang termasuk dalam portofolio Low.

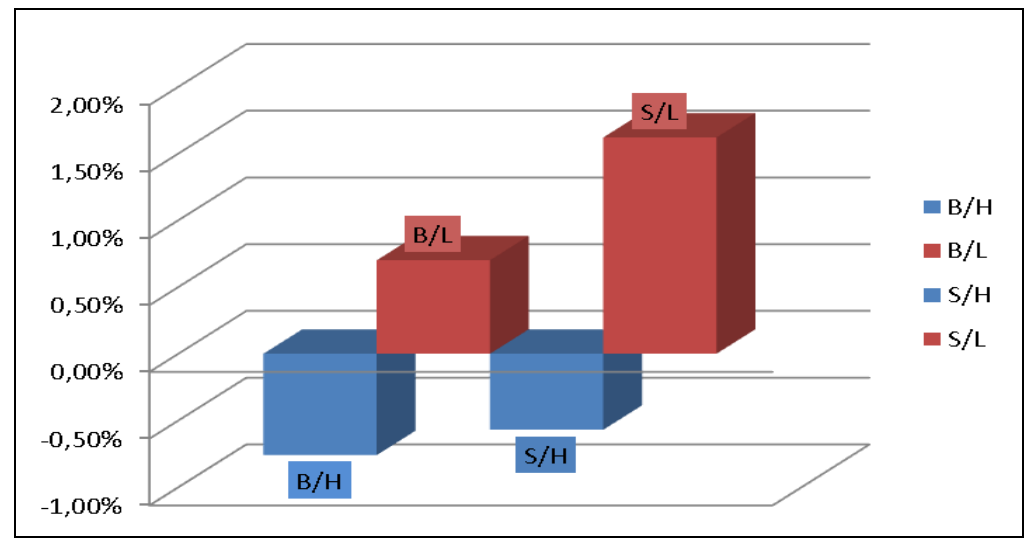

Gambar 2. Portofolio High vs Porfolio Low Sumber: data yang diolah, 2017 
Gambar 2 menunjukkan bahwa berdasarkan rata-rata return yang diperoleh, perusahaan yang termasuk dalam low book to market equity secara umum lebih bagus karena memberikan rata-rata return yang lebih tinggi dibandingkan high book to market equity. Pada portofolio HML tidak ditemukan adanya value effect atau terjadi growth effect karena return pada portofolio dengan growth stocks (low book to market equity) mengungguli return pada portofolio dengan value stocks (high book to market equity).

Terdapat empat uji asumsi klasik yang dilakukan agar dapat melakukan uji regresi yaitu uji normalitas, uji multikolinieritas, uji autokorelasi, dan uji heteroskedastisitas. Hasil uji asumsi klasik dalam penelitian ini menunjukkan bahwa data lolos pada semua uji asumsi klasik sehingga dapat dilakukan pengujian selanjutnya yaitu uji regresi.

Analisis CAPM dalam penelitian ini menggunakan regresi linier sederhana dan analisis FF3FM menggunakan regresi linier berganda. Model regresi CAPM yaitu:

$$
R i-R f=a+\beta i(R m-R f)+e
$$

Keterangan:

$\mathrm{Ri}=$ Return saham i historis (bulanan),

$\mathrm{Rf} \quad=$ Tingkat keuntungan bebas risiko (SBI bulanan),

a $=$ Konstanta,

$\beta \mathrm{i}=$ Beta pasar koefisien regresi,

$\mathrm{Rm}=$ Return pasar bulanan Indeks Harga Saham Gabungan (IHSG),

e $\quad=$ Error term.

Model regresi FF3FM yaitu:

$$
R i-R f=a+\beta i(R m-R f)+\gamma i(S M B)+\delta i(H M L)+e
$$

Keterangan: 
Ni Putu Desy Ratna Dewi dan I Wayan Suartana. Komparasi Kinerja...

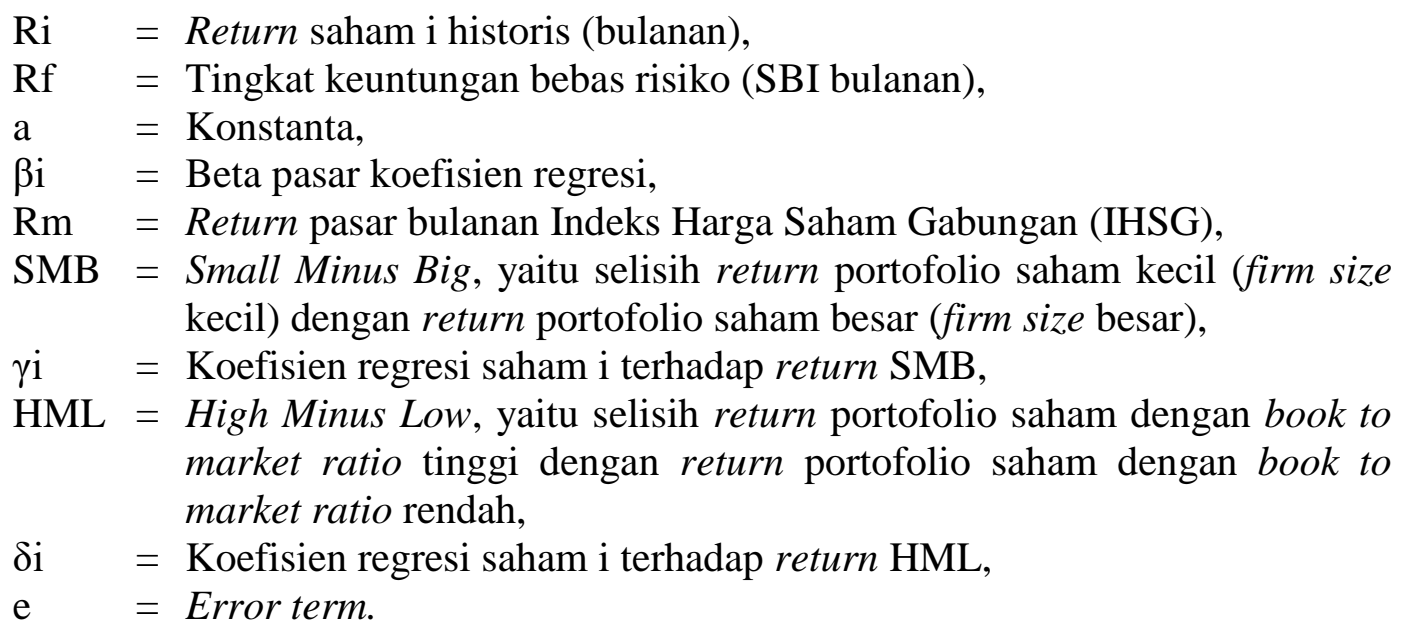

Melalui uji regresi dapat diketahui pengaruh faktor-faktor tersebut baik secara parsial maupun simultan serta seberapa besar faktor-faktor tersebut dapat menjelaskan naik turunnya return. Hasil pengujian regresi pada CAPM dapat dilihat pada Tabel 3 .

Tabel 3.

\section{Hasil Regresi CAPM}

\begin{tabular}{ccccccc}
\hline \multirow{2}{*}{ SIZE } & \multicolumn{7}{c}{ BOOK TO MARKET EQUITY PORTOFOLIOS } \\
\cline { 2 - 7 } PORTOFOLIOS & Low & Medium & High & Low & Medium & High \\
\hline \multicolumn{7}{c}{ a coefficient } \\
Small & 0,015 & 0,005 & $-0,007$ & $3,176^{*}$ & 0,759 & $-1,010$ \\
Big & 0,006 & 0,003 & $-0,009$ & 1,927 & 0,922 & $-1,507$ \\
\hline \multicolumn{7}{c}{$\beta$ coefficient } \\
Small & 0,817 & 1,674 & 1,661 & $6,249^{*}$ & $9,657^{*}$ & $8,274^{*}$ \\
Big & 1,045 & 1,485 & 1,043 & $12,652^{*}$ & $18,197^{*}$ & $6,620^{*}$ \\
\hline \multicolumn{7}{c}{ Adjusted $R$ square } \\
Small & $39,2 \%$ & $61,0 \%$ & $53,3 \%$ & & & \\
Big & $72,9 \%$ & $84,8 \%$ & $42,1 \%$ & & & \\
\hline Sumber: data yang diolah, 2017 &
\end{tabular}

Tabel 3 menunjukkan bahwa satu dari enam portofolio nilai intersepnya (koefisien $\alpha$ ) secara statistik signifikan berbeda dari nol pada tingkat signifikansi 5\%. Hasil ini menunjukkan bahwa return portofolio $\mathrm{B} / \mathrm{H}, \mathrm{B} / \mathrm{M}, \mathrm{B} / \mathrm{L}, \mathrm{S} / \mathrm{H}$, dan S/M dapat dijelaskan secara penuh oleh market risk premium pada CAPM. 
Hasil regresi pada Tabel 3 membuktikan bahwa variabel market risk premium berpengaruh positif terhadap return pada setiap jenis portofolio $\mathrm{B} / \mathrm{H}$, B/M, B/L, S/H, S/M, dan S/L. Hasil ini menunjukkan bahwa semakin tinggi nilai market risk premium maka semakin tinggi return yang diterima. Market risk premium menggambarkan risiko dari suatu investasi. Dengan demikian, maka semakin besar market risk premium, semakin besar return portofolio $\mathrm{B} / \mathrm{H}, \mathrm{B} / \mathrm{M}$, B/L, S/H, S/M, dan S/L yang tergabung dalam kelompok saham Indeks Kompas 100.

Hasil penelitian ini mendukung konsep CAPM yaitu high risk high return. Jadi, investor akan menargetkan risk premium yang tinggi pada sahamsaham yang berisiko tinggi untuk mengeliminasi risiko tersebut. Hasil penelitian sesuai dengan penelitian Pitriyanti, et al. (2015), Susanti (2013), Sudiyatno dan Irsad (2013), Gan, et al. (2013), Ismanto (2011), O’Brien (2007), Jianlong, et al. (2015), Bhatnagar dan Ramlogan (2012), Rossi (2012) yang menemukan bahwa market risk premium pada CAPM berpengaruh positif terhadap return saham.

Nilai adjusted $R$ square menunjukkan seberapa besar variabel independen mempengaruhi variabel dependen. Rata-rata nilai adjusted $R$ square pada CAPM adalah 58,9\%. Pada model CAPM, portofolio B/M memiliki nilai adjusted $R$ square tertinggi yaitu $84,8 \%$ dan nilai terendah pada portofolio $\mathrm{S} / \mathrm{L}$ sebesar 39,2\%. Rata-rata nilai adjusted $R$ square pada kelompok portofolio big 15,4\% lebih tinggi dibandingkan nilai adjusted $R$ square pada kelompok portofolio small. Hal ini mengindikasikan bahwa market risk premium lebih mampu menjelaskan tingkat return pada kelompok portofolio big dibandingkan 
Ni Putu Desy Ratna Dewi dan I Wayan Suartana. Komparasi Kinerja...

pada kelompok portofolio small. Penelitian ini juga menemukan bahwa nilai adjusted $R$ square pada kelompok portofolio low lebih tinggi daripada nilai adjusted $R$ square pada kelompok portofolio high.

CAPM menjelaskan perilaku return dan risiko hanya ditentukan oleh pasar, sedangkan Fama dan French (1993) menambahkan faktor fundamental perusahaan yaitu ukuran perusahaan (firm size) dan book to market. Tiga variabel penjelas dalam estimasi return ekspektasi FF3FM meliputi market risk premium, size premium (diproksikan dengan $\mathrm{SMB}$ ), dan book to market premium (diproksikan dengan HML). Untuk mengetahui signifikansi masing-masing variabel dalam FF3FM dilakukan analisis regresi linear berganda. Hasil pengujian regresi pada FF3FM dapat dilihat pada Tabel 4.

Tabel 4.

Hasil regresi FF3FM

\begin{tabular}{|c|c|c|c|c|c|c|}
\hline \multirow{2}{*}{$\begin{array}{c}\text { SIZE } \\
\text { PORTOFOLIOS }\end{array}$} & \multicolumn{6}{|c|}{ BOOK TO MARKET EQUITY PORTOFOLIOS } \\
\hline & Low & Medium & High & Low & Medium & High \\
\hline & \multicolumn{3}{|c|}{ a coefficient } & \multicolumn{3}{|c|}{$\mathrm{t}$} \\
\hline Small & 0,004 & 0,011 & 0,002 & 1,171 & $2,425^{*}$ & 0,665 \\
\hline \multirow[t]{2}{*}{ Big } & 0,005 & 0,006 & 0,007 & 1,949 & 1,777 & 1,879 \\
\hline & \multicolumn{3}{|c|}{$\beta$ coefficient } & \multicolumn{3}{|c|}{$\mathrm{t}$} \\
\hline Small & 0,908 & 1,358 & 1,214 & $9,119 *$ & $11,189 *$ & $13,982 *$ \\
\hline \multirow[t]{2}{*}{ Big } & 1,151 & 1,485 & 0,844 & $16,887 *$ & $18,293 *$ & $8,280^{*}$ \\
\hline & \multicolumn{3}{|c|}{$\gamma$ coefficient } & \multicolumn{3}{|c|}{$\mathrm{t}$} \\
\hline Small & 0,176 & 0,197 & 0,264 & $6,119^{*}$ & $5,590 *$ & $10,484 *$ \\
\hline \multirow[t]{2}{*}{ Big } & $-0,102$ & $-0,072$ & $-0,189$ & $-5,174 *$ & $-3,040 *$ & $-6,413 *$ \\
\hline & \multicolumn{3}{|c|}{$\delta$ coefficient } & \multicolumn{3}{|c|}{$\mathrm{t}$} \\
\hline Small & $-0,229$ & 0,240 & 0,349 & $-5,821^{*}$ & $4,990 *$ & $10,167 *$ \\
\hline Big & $-0,056$ & 0,049 & 0,366 & $-2,061^{*}$ & 1,539 & $9,067 *$ \\
\hline \multicolumn{7}{|c|}{ Adjusted $R$ square } \\
\hline Small & $68,6 \%$ & $82,9 \%$ & $92,2 \%$ & & & \\
\hline Big & $83,6 \%$ & $86,6 \%$ & $78,4 \%$ & & & \\
\hline
\end{tabular}

Sumber: data yang diolah, 2017

Tabel 4 menunjukkan bahwa satu dari enam portofolio nilai intersepnya (koefisien $\alpha$ ) secara statistik signifikan berbeda dari nol pada tingkat signifikansi 
5\%. Hasil ini menunjukkan bahwa return portofolio B/H, B/M, B/L, S/H, dan S/L dapat dijelaskan secara penuh oleh market risk premium, size premium, dan book to market premium pada FF3FM.

Berdasarkan Tabel 4 dapat dilihat bahwa market risk premium pada FF3FM berpengaruh positif terhadap return saham pada semua portofolio yang dibentuk. Hal ini berarti bahwa market factor memiliki peran penting dalam menjelaskan variasi return saham. Regresi SMB dalam FF3FM menunjukkan bahwa slope dari size premium (SMB) pada portofolio B/H, B/M, B/L bertanda negatif. Berbeda dengan portofolio $\mathrm{B} / \mathrm{H}, \mathrm{B} / \mathrm{M}, \mathrm{B} / \mathrm{L}$, hasil pengujian regresi pada FF3FM menunjukkan bahwa slope dari size premium (SMB) pada portofolio S/H, S/M, S/L bertanda positif. Hal ini berarti ukuran perusahaan berpengaruh terhadap return saham dan koefisien atau slope regresi yang lebih tinggi mengindikasikan return yang lebih tinggi pada kelompok portofolio small.

Hasil penelitian ini sesuai dengan Fama dan French (1993), Banz (1981), Bhatnagar dan Ramlogan (2012), Gan, et al. (2013), Hardianto dan Suherman (2009) yang menemukan bahwa saham dengan kapitalisasi pasar kecil dapat mengungguli saham dengan kapitalisasi pasar yang besar, sehingga small firm effect teridentifikasi di Pasar Modal Indonesia. Small firm effect merupakan suatu kondisi ketika return saham perusahaan-perusahaan dari kategori small firm mengungguli saham-saham dari kategori large firm. Sehingga strategi pemilihan portofolio berdasarkan size effect ini akan memberikan return yang outperform.

Size (SMB) dalam penelitian ini merupakan ukuran perusahaan yang merepresentasikan selisih return portofolio saham kecil (small firm size) dengan 
Ni Putu Desy Ratna Dewi dan I Wayan Suartana. Komparasi Kinerja...

return portofolio saham besar (big firm size). Investor memiliki persepsi bahwa perusahaan dengan kapitalisasi kecil cenderung tidak stabil dan lebih sensitif terhadap berbagai risiko dibanding perusahaan dengan kapitalisasi besar. Ketidakpastian dan risiko yang lebih besar ini mendorong investor untuk mensyaratkan tambahan return yang lebih besar juga dibanding perusahaan dengan kapitalisasi besar yang jauh lebih stabil dan lebih tidak berisiko.

Koefisien beta HML pada semua portofolio signifikan kecuali pada portofolio B/M. Rata-rata koefisien beta portofolio high lebih tinggi dari rata-rata portofolio low. Besarnya koefisien beta book to market premium pada portofolio B/L dan S/L bertanda negatif pada tingkat signifikansi 5\%. sedangkan koefisien beta pada portofolio $\mathrm{B} / \mathrm{H}, \mathrm{S} / \mathrm{H}$, dan $\mathrm{S} / \mathrm{M}$ bertanda positif pada tingkat signifikansi 5\%. Hal ini memberikan bukti bahwa book to market premium memiliki pengaruh dalam menjelaskan variasi return saham.

Secara umum penelitian ini menerima penelitian Fama dan French (1993), Gan, et al. (2013), Bhatnagar dan Ramlogan (2012), Hardianto dan Suherman (2009) yang menemukan bahwa uji regresi pada growth stocks (low $\mathrm{BE} / \mathrm{ME}$ ) mengandung arah yang negatif sedangkan pada value stocks (high $\mathrm{BE} / \mathrm{ME})$ mengandung arah yang positif.

Rata-rata nilai adjusted $R$ square pada FF3FM adalah 82,1\%. Pada model ini, portofolio $\mathrm{S} / \mathrm{H}$ memiliki nilai adjusted $R$ square tertinggi yaitu $92,2 \%$ dan nilai terendah pada portofolio $\mathrm{S} / \mathrm{L}$ sebesar $68,6 \%$. Rata-rata nilai adjusted $R$ square pada kelompok portofolio big 1,6\% lebih tinggi dibandingkan nilai adjusted $R$ square pada kelompok portofolio small. Penelitian ini juga 
menemukan bahwa nilai adjusted $R$ square pada kelompok portofolio high lebih tinggi daripada nilai adjusted $R$ square pada kelompok portofolio low sebesar $9,2 \%$.

Gambar 3 menyajikan komparasi nilai adjusted $R$ square CAPM dan FF3FM pada portofolio B/H, B/M, B/L, S/H, S/M, dan S/L.

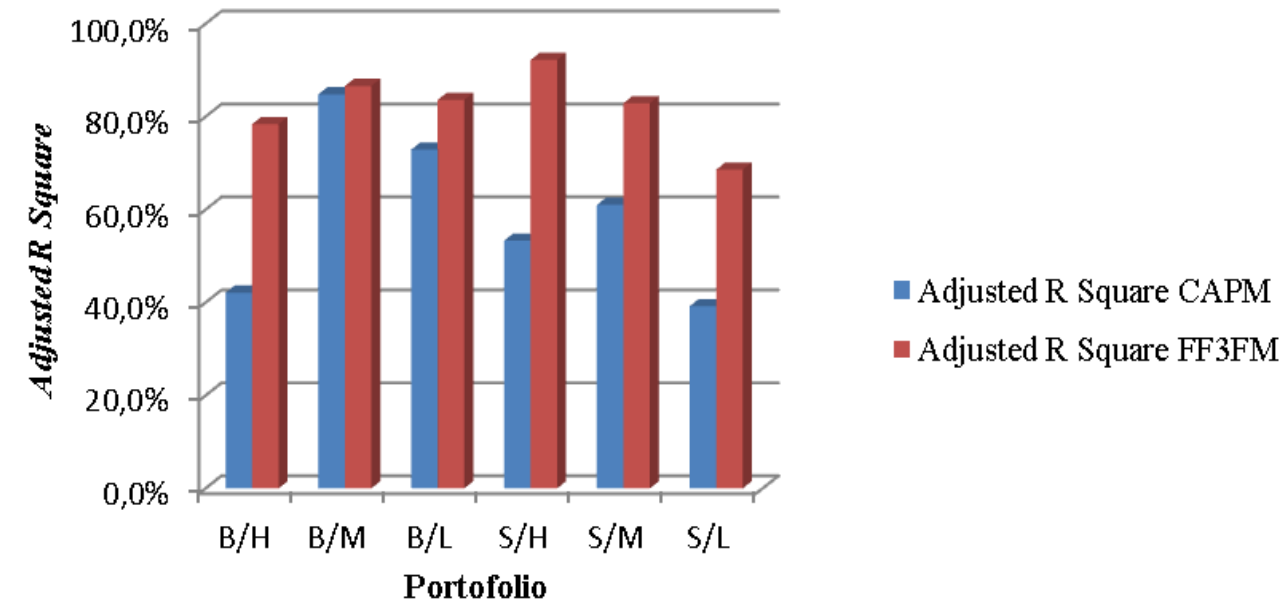

Gambar 1. Komparasi Adjusted R Square CAPM dan FF3FM Sumber: data yang diolah, 2017

Nilai adjusted $R$ square model CAPM dan FF3FM pada portofolio $\mathrm{B} / \mathrm{H}$, $\mathrm{B} / \mathrm{M}, \mathrm{B} / \mathrm{L}, \mathrm{S} / \mathrm{H}, \mathrm{S} / \mathrm{M}$, dan $\mathrm{S} / \mathrm{L}$ menunjukkan bahwa market risk premium, size premium dan book to market premium pada model FF3FM lebih baik dalam menjelaskan tingkat return dibandingkan CAPM pada kelompok saham Indeks Kompas 100 di Bursa Efek Indonesia. Penelitian ini sesuai dengan penelitian Bhatnagar dan Ramlogan (2012), Gan, et al. (2013), O’ Brien (2007), Pitriyanti, et al. (2015), dan Surono (2016) yang menemukan bahwa FF3FM lebih superior dalam menjelaskan variasi return saham yang diharapkan dibandingkan CAPM. 
Ni Putu Desy Ratna Dewi dan I Wayan Suartana. Komparasi Kinerja...

CAPM dan FF3FM merupakan dua model penilaian aset yang samasama menggunakan market risk premium untuk menjelaskan variasi return, tetapi FF3FM menambah dua variabel dalam modelnya yaitu size premium dan book to market premium. Kegagalan CAPM dalam mengungguli FF3FM disebabkan dari asumsi yang digunakan. CAPM dan FF3FM menggunakan asumsi berbeda pada modelnya yang dapat dilihat pada Tabel 5 .

Tabel 5.

Asumsi pada CAPM dan FF3FM

\begin{tabular}{|c|c|}
\hline Asumsi pada CAPM & Asumsi pada FF3FM \\
\hline $\begin{array}{l}\text { Semua investor mempunyai distribusi probabilitas } \\
\text { tingkat return di masa depan yang identik, karena } \\
\text { mempunyai harapan atau ekspektasi yang hampir sama. }\end{array}$ & \multirow{8}{*}{ Size dan value merupakan faktor risiko. } \\
\hline $\begin{array}{l}\text { Semua investor mempunyai satu periode waktu yang } \\
\text { sama, misalnya satu tahun. }\end{array}$ & \\
\hline $\begin{array}{l}\text { Semua investor dapat meminjamkan sejumlah dananya } \\
\text { (lending) atau meminjam sejumlah dana (borrowing) } \\
\text { dengan jumlah yang tidak terbatas pada tingkat suku } \\
\text { bunga bebas risiko. }\end{array}$ & \\
\hline Tidak ada biaya transaksi. & \\
\hline Tidak terjadi inflasi. & \\
\hline $\begin{array}{l}\text { Tidak ada pajak pendapatan pribadi sehingga investor } \\
\text { mempunyai pilihan yang sama untuk mendapatkan } \\
\text { dividen atau capital gain. }\end{array}$ & \\
\hline $\begin{array}{l}\text { Investor adalah penerima harga (price takers). Investor } \\
\text { individual tidak dapat mempengaruhi harga dari suatu } \\
\text { aktiva dengan kegiatan membeli atau menjual aktiva } \\
\text { tersebut. }\end{array}$ & \\
\hline Pasar modal dalam kondisi ekuilibrium. & \\
\hline
\end{tabular}

Sumber: Tandelilin, 2010:187 dan Estrada, 2011

Asumsi-asumsi yang digunakan dalam CAPM oleh beberapa ahli dianggap kurang realistis sehingga sulit untuk melakukan uji empiris yang valid. Menurut Fama dan French (2004), masalah empiris CAPM dapat merefleksikan kegagalan teoritis yang merupakan hasil dari banyak asumsi penyederhanaan tetapi juga dapat disebabkan kesulitan untuk menerapkan uji model yang valid. Asumsi penyederhanaan dan kesulitan dalam menerapkan uji model yang valid 
akan menyebabkan hasil pengujian tidak sesuai dengan yang diharapkan dalam CAPM.

Berdasarkan hasil penelitian, FF3FM merupakan model yang lebih baik untuk diaplikasikan dibandingkan dengan CAPM karena dua alasan. Pertama, nilai adjusted $R$ square pada masing-masing model menunjukkan bahwa FF3FM lebih baik dalam menjelaskan variasi return sehingga FF3FM merupakan model yang lebih akurat. Kedua, meskipun model CAPM terlihat sederhana, masalah empiris dalam CAPM mungkin menyebabkan aplikasinya menjadi invalid (Fama dan French, 2004).

\section{SIMPULAN DAN SARAN}

Berdasarkan pembahasan sebelumnya, variabel market risk premium berpengaruh positif terhadap return pada enam portofolio yang dibentuk dalam CAPM dan FF3FM. Hasil uji parsial (uji t) menunjukkan variabel size premium berpengaruh positif pada return portofolio $\mathrm{S} / \mathrm{H}, \mathrm{S} / \mathrm{M}$, dan $\mathrm{S} / \mathrm{L}$ dan berpengaruh negatif pada return portofolio B/H, B/M, dan B/L. Ditemukan adanya small firm effect pada pasar modal Indonesia, hal ini dilihat dari rata-rata size premium (diproksikan dengan SMB) positif. SMB yang positif menunjukkan bahwa return saham perusahaan dengan kapitalisasi pasar kecil mengungguli return saham perusahaan dengan kapitalisasi pasar besar.

Variabel book to market premium (diproksikan dengan HML) berpengaruh positif pada return portofolio $\mathrm{B} / \mathrm{H}, \mathrm{S} / \mathrm{H}$, dan $\mathrm{S} / \mathrm{M}$ dan berpengaruh negatif pada return portofolio $\mathrm{B} / \mathrm{L}$, dan $\mathrm{S} / \mathrm{L}$ sedangkan pada return portofolio $\mathrm{B} / \mathrm{M}$ variabel 
Ni Putu Desy Ratna Dewi dan I Wayan Suartana. Komparasi Kinerja...

book to market premium tidak berpengaruh. Tidak ditemukan adanya value effect pada pasar modal Indonesia, hal ini dapat dilihat dari nilai rata-rata HML negatif yang berarti return perusahaan dengan book to market premium rendah mengungguli return perusahaan dengan book to market premium yang tinggi.

Hasil uji $\mathrm{F}$ pada FF3FM menunjukkan bahwa variabel market risk premium, size premium, dan book to market premium secara simultan berpengaruh terhadap return portofolio $\mathrm{S} / \mathrm{H}, \mathrm{S} / \mathrm{M}, \mathrm{S} / \mathrm{L}, \mathrm{B} / \mathrm{H}, \mathrm{B} / \mathrm{M}$, dan $\mathrm{B} / \mathrm{L}$. Nilai adjusted $R$ square CAPM berada pada rentang 39\%-84\% sedangkan pada FF3FM nilai adjusted $R$ square berada pada rentang $68 \%-92 \%$, hasil ini menunjukkan bahwa kemampuan FF3FM dalam menjelaskan return lebih baik dibandingkan CAPM pada perusahaan yang masuk kelompok saham Indeks Kompas 100 di Bursa Efek Indonesia.

Penelitian ini diharapkan dapat bermanfaat bagi investor, bagi perusahaan, dan bagi penelitian-penelitian selanjutnya. Berdasarkan simpulan yang ada, peneliti dapat memberikan saran-saran yaitu investor yang berinvestasi di pasar modal dapat melakukan analisis dengan FF3FM. Asumsi-asumsi yang melandasi CAPM sangat banyak dan terlihat tidak realistis sehingga membuat model ini gagal mengungguli FF3FM. FF3FM juga dapat digunakan untuk mengestimasi return apabila asumsinya terpenuhi yaitu size dan value merupakan faktor risiko yang mempengaruhi variasi return.

Hasil penelitian ini dapat digunakan oleh investor dalam melakukan seleksi portofolio dan melakukan evaluasi kinerja portofolio. Pembentukan portofolio dapat didasarkan pada faktor size dan book to market karena 
berdasarkan penelitian ini kedua faktor tersebut berpengaruh terhadap return. Investor juga dapat mempertimbangkan fenomena small firm effect dan growth effect yang terjadi di Pasar Modal Indonesia dalam membentuk portofolio.

Penelitian ini menggunakan metode Fama dan French $(1992,1993)$ dalam membentuk portofolio yaitu membagi perusahaan menjadi dua kelompok berdasarkan size dan tiga kelompok berdasarkan rasio BE/ME. Bagi penelitian selanjutnya dapat menggunakan cara pembagian kelompok dengan jumlah yang berbeda sehingga dapat dibandingkan apakah pilihan tersebut sensitif terhadap kinerja masing-masing model.

\section{REFERENSI}

Bank Indonesia. 2017. Suku Bunga Sertifikat Bank Indonesia. http://www.bi.go.id/id/moneter/operasi/suku-bunga-sbi/Default.aspx (diunduh tanggal 20 Juli 2017).

Banz, R.W., 1981. The relationship Between Return and Market Value Of Common Stocks. Journal of Financial Economics, 9: 3-18.

Bhatnagar, S.C., Ramoglan, R. 2012. The Capital Asset Pricing Model Versus The Three Factor Model: A United Kingdom Perspective. International Journal of Business and Social Research, 2: 51-65.

Choudhary, K., Choudary, S. 2010. Testing Capital Asset Pricing Model: Empirical Evidences from Indian Equity Market. Eurasian Journal of Business and Economics 2010, 3 (6): 127-138.

Davis, J. L., Fama, E.F., French, K.R. 2000. Characteristics, Covariances, and Average Returns: 1929 to 1997. The Journal of Finance, 55 (1): 389-406.

Drew, M. E., Naughton, T., Veeraraghavan, M. 2003. Firm Size, Book-to-Market Equity and Security Returns: Evidence from the Shanghai Stock Exchange. Australian Journal of Management, 28 (2): 119-139.

Estrada, Javier. 2011. The Three Factor Model: A Practitioner's Guide. Journal of Applied Corporate Finance, 23 (2): 77-84 
Ni Putu Desy Ratna Dewi dan I Wayan Suartana. Komparasi Kinerja...

Fama, E.F. dan French, R.F. 1992. The Cross-Section of Expected Stock Returns. Journal of Finance, 47: 427-465.

.1993. Common Risk Factors In The Returns On Stocks And Bonds. Journal of financial Economics, 33: 3-56.

.1996. Multifactor Explanations of Asset Pricing Anomalies. Journal of Finance, 51 (1): 55 - 84.

.1998. Value versus Growth: The International Evidence. The Journal of Finance, 53 (6): 1976 - 1999.

.2004. The Capital Asset Pricing Model: Theory and Evidence. Journal of Economic Perspective, 18 (3): 25-46.

Hardianto, D., dan Suherman. 2009. Pengujian Fama-French Three Factor Model di Indonesia. Jurnal Keuangan dan Perbankan, 13 (2): 198 - 208.

Harsalim, N. 2013. Pengaruh Market Risk, Size, Book to Market Ratio, dan Earnings Price Ratio Terhadap Return Saham Sektor Miscellaneous Industry di BEI Periode 2006-2012. Calyptra: Jurnal Ilmiah Mahasiswa Universitas Surabaya, 2 (2): 1-20.

IDX. 2017. Laporan Keuangan Tahunan. http://www.idx.co.id/id$\mathrm{id} /$ beranda/perusahaantercatat/laporankeuangandantahunan.aspx (diunduh tanggal 20 Juli 2017).

Ismanto, H. 2011. Analisis Pengaruh Ukuran Perusahaan, Book to Market Value, dan Beta terhadap Return Saham di BEI. Jurnal Ekonomi \& Pendidikan, 8 (2): $185-206$.

Jianlong, W., Jaaman, S.H., dan Samsudin, H.B. 2015. Empirical Study on China Stock Market Base on Fama-French Model. Indian Journal of Science and Technology, 8 (11): 1-9.

Lintner, J. 1965. Security Prices, Risk, and Maximal Gains from Diversification. Journal of Finance 4: 587-615.

Markowitz, H. 1952. Portfolio Selection. The Journal of Finance, 1: 77-91.

Mossin, J. 1969. Security Pricing and Investment Criteria in Competitive Markets. The American Economics Review, 5: 748-756.

O' Brien, M.A. 2008. Size and Book-to-Market Factors in Australia. https://papers.ssrn.com/sol3/papers.cfm?abstract_id=1206542 (diunduh tanggal 2 Juni 2017).

Pitriyanti, K.M., Dharmawan, K., Gandhiadi, G.K. 2015. Perbandingan Capital Asset Pricing Model (CAPM) dan Three Factors Model Fama and French 
(TFMFF) dalam Mengestimasi Return Saham. E-Jurnal Matematika, 4 (4): 181187.

Rahim, R.A., dan Nor, A.S.M. 2006. A Comparison between Fama and French Model and Liquidity-Based Three-Factor Models in Predicting The Portfolio Returns. Asian Academy of Management Journal of Accounting and Finance, 2 (2): $43-60$.

Rossi, F. 2012. The Three-Factor Model: Evidence from the Italian Stock Market. Research Journal of Finance and Accounting. 3 (9): 151-160.

Saputra, D.I., dan Murtini, U. 2008. Perbandingan Fama and French Three Factor Model dengan Capital Asset Pricing Model. Jurnal Riset Akuntansi dan Keuangan, 4 (2): 132-145.

Sekarwati, H., Margasari, N. 2016. Penggunaan Metode Capital Asset Pricing Model dalam Menentukan Keputusan Berinvestasi Saham (Studi pada Saham Indeks Kompas 100 di Bursa Efek Indonesia). http://journal.student. uny. ac.id/ojs/ index.php/ jmbi /article/download/5044/4710 (diunduh tanggal 28 Juni 2017).

Sharpe, W.F. 1964. Capital Asset Prices: A Theory of Market Equilibrium under Conditions of Risk. Journal of Finance, 19: 425-442.

Simangunsong, Y., dan Wirama, D. 2014. Pengujian Validitas Empiris Capital Asset Pricing Model Di Pasar Modal Indonesia. Jurnal Ilmiah Akuntansi dan Bisnis, 9 (1): 57 - 64.

Stattman, W.F. 1980. Book Value and stock returns. The Chicago MBA: A Journal of Selected Papers, 4: 25-45.

Sudiyatno, B., dan Irsad, M. 2011. Study of Three Factors Model Fama and French in Indonesia Stock Exchange (Study on the Stock LQ 45). Jurnal Bisnis dan Ekonomi, 18 (2): 126-136.

Sugiyono. 2013. Metode Penelitian Bisnis. Bandung: CV Alfabeta.p. 46-80.

Sujarweni, Wiratna. 2012. SPSS untuk Penelitian. Yogyakarta: Pustaka Baru Press.

Surono, Y. 2016. Memprediksi Return Saham: Keakuratan 2 (Dua) Model Fama French dan CAPM. Eksis, 7 (2): 117-132.

Susanti, N. 2013. Pengujian Fama French Three Factor Model pada Perusahaan di Indonesia yang Sahamnya Terdapat di LQ 45 Tahun 2005 - 2009. Forum Keuangan \& Bisnis, 2: 535-559.

Tandelilin, E. 2010. Portofolio dan Investasi, Teori dan Aplikasi. Edisi Pertama. Yogyakarta: Kanisius. 
Ni Putu Desy Ratna Dewi dan I Wayan Suartana. Komparasi Kinerja...

Wakyiku, D. 2010. Testing the Capital Asset Pricing Model (CAPM) on the Uganda Stock Exchange. https://arxiv.org/abs/1101.0184v1 (diunduh tanggal 2 Juni 2017).

Yahoo Finance. 2017. Harga Penutupan Saham Bulanan. https://finance.yahoo.com/ (diunduh tanggal 20 Juli 2017).

Yeswanto, A., dan Mardani, R.M. 2015. Menguji Model Tiga Faktor Fama dan French dalam Mempengaruhi Return Saham Studi Pada Saham LQ 45 di Bursa Efek Indonesia. Warta Ekonomi, 4 (1): 23-32. 